\title{
The Vocational Potential of Anthropology: Teaching Organisational Research Through Practitioner Archives
}

\author{
Dr Elizabeth Cory-Pearce and Juliet Scott \\ Tavistock Institute of Human Relations
}

\begin{abstract}
In this article we posit the potential utility of a practitioner archive as data for teaching those studying anthropology to understand and perhaps also to practice organisational research and consultancy ethnographically. We address both the value and challenges of taking a purposively ethnographic approach to organisational work, as these both reflect and may also inform the values and challenges of teaching ethnographically more generally within anthropology programmes. The Tavistock Institute of Human Relations is a not-for-profit social science research and organisational consultancy of charitable status, based in London and in formal operation since 1947. Drawing on archived historical projects of the Institute, we illustrate and explore how a distinctively ethnographic approach to action-orientated research (research undertaken in and with client organisations, which is put into action by implementing changes which are designed to address the organisation's needs) was achieved in a context of market and other constraints.
\end{abstract}

\section{Introduction}

This article seeks to present the Tavistock Institute's historical project work and methodological tradition now preserved, catalogued, and publically available at the Wellcome Library, as a resource with which to teach within the social sciences an ethnographically informed approach to organisational work. ${ }^{i}$ In order to present to you the heuristic value of this archive, we address some questions that teachers of anthropology might have about the Tavistock archive, and offer up some insights that may encourage and enable teachers to make use of the archive in the ways we set out to suggest here. Some of these questions include: what distinctiveness to organisational work can a background in anthropology bring? What might an anthropologically informed approach to organisational research look like? And, what historical examples and case studies might be drawn upon in teaching to bring these positions across? By introducing the reader to some key industrial projects, we aim to illustrate the depth, richness and utility that an ethnographic dimension can bring to the understanding of organisational and workplace dynamics, and their effect on both economic productivity and the quality of people's working life.

In recognising an important ethnographic component to Tavistock work - itself a cherished yet at times contested or rejected part of the Tavistock methodological tradition - we invite teachers of anthropology to revisit, reincorporate and ideally redistribute this important dimension of historical anthropological practice, which currently receives far greater recognition and use within the various fields of organisational and management studies (see, for example, Burnes and Cooke 2013, and Cummings et al 2016, for recent critical revisions of their fields). In demonstrating the value of taking an ethnographic approach to action-orientated research in and with industry and other organisations, the paper also aims to offer to those working in the field of teaching anthropology clear examples of the vocational potential of an anthropological education as both a scholarly and applied professional calling. ${ }_{\text {.i }}$ In the following sections, we illustrate and explore how Tavistock researchers have nurtured ethnographic sensibilities in their work. However, before doing so, in the next two sections we first set out a brief account of the formation of the Tavistock Institute and the genesis of its archive at Wellcome to illustrate both the relevance of the Institute's work and archive to the history of anthropology, and to suggest some reasons for its current invisibility.iii 


\section{The formation of the Tavistock Institute}

During the Second World War, a group of social scientists known as 'the Tavistock Group' were commissioned to design and deliver innovative services to the British Army, including the War Officer Selection Boards (aimed at working with soldiers to devise solutions to problems of recruitment into military leadership roles), and the Civil Resettlement Units (aimed at supporting the healthy reincorporation of those with war service experience back into civilian life) (Abraham 2013; White n.d. [2016]). Their work at the Northfield Military Hospital for instance comprised group social experiments that explored, in situ, the dynamics of group formation and the delivery of tasks by leaderless groups, the learning from which was then applied to war officer selection and war service. At the core of this work was the understanding of human group dynamics - i.e. the overt and also the covert and sometimes unconscious emotions that routinely underpin the decisions people make - which remains key to the work done by the Tavistock today.

After the war, the Tavistock Group became the Tavistock Clinic, out of which the Tavistock Institute of Human Relations was formed when the Clinic (as a specifically clinical practice) became incorporated into the newly established National Health Service. iv In the wake of two world wars, the Institute's work was generally concerned with the dual purpose of growing productivity in a period requiring rapid economic recovery, whilst at the same time ensuring the humaneness of work and maintaining worker morale. Already apparent in the wartime work, is an effort to advance the social sciences through direct and practical involvement with human and social problems, and in particular the tensions between workers, management and leadership as they appear within organisations and services. So, for instance, at Northfield Military Hospital it is soldiers themselves who are immediately part of developing an understanding of the issues at stake, and devising and testing out proposed solutions. In the post-war period, this action-orientated approach was applied to social and economic challenges faced by large government bodies, public services and industry. For instance, in its work for Unilever the Tavistock Institute adapted the war officer selection work to meet the client's managerial selection process needs, creating an early form of what later became known as the 'assessment centre' approach, which continues to be used today (White and Monninger n.d. [2017]).v This work signals a key post-war shift to organisational consultancy in a rapidly industrialising consumer society.

Establishing its own journal Human Relations in 1947 (Neumann 2005), from the outset Institute staff endeavoured to publish articles on their work. However, just one year in, the first annual report of the Institute notes this was already encountering a serious problem: as a 'fully technical' journal, Human Relations was already losing touch with those audiences (namely clients) more interested in 'up-to-date reports' on current work (Tavistock Institute of Human Relations Annual Report, 1948). Providing a journal section dedicated to 'Briefer Studies' was aimed at ameliorating this, however it alone could not overcome the tension between 'the development of integrative work in social science' on the one hand, and 'difficulties in maintaining the supply of interdisciplinary technical articles' on the other, articles for which the journal was primarily founded (ibid). In other words, the Institute had soon found itself to be occupying a difficult space "between academic social science on the one side and a commercial consultancy practice on the other" (Miller 1993: vii).

Given that action-orientated research "by its nature, is problem-centred not discipline-centred" (Miller 1993: viii), the work of the Institute may go overlooked by relevant scholarly audiences such as anthropology unless its disciplinary relevance is made explicit. Furthermore, given that the bulk of the Institute's research remains unpublished as it is produced for clients who largely do not commission academic articles, the archive represents a significant data resource. It comprises research that is neither necessarily framed nor has it been disseminated within a single academic discipline. Rich in historical, anthropological, sociological and psychoanalytical approaches and insights into the organisations in which we live and work, the archive charts the formation and development of the Institute's theoretical and methodological approaches to understanding human and group dynamics within organisations, such that they can be acted upon and ideally improved.

\section{Archiving ourselves: an organisational journey}

Prior to its cataloguing at Wellcome, the uncatalogued Tavistock archival material comprised over a thousand boxes of documents from the administration and daily running of the organisation, as well as correspondence, raw data, field notes, reports, draft publications and other published material (such as pamphlets, bulletins, etc.) dating back to the 1940s. Until 2012, this material had been maintained in a salt mine in Cheshire, a dedicated offsite storage space where it was subject to fire and water damage, and inaccessible to Institute staff and the public at large. The project of bringing the archive to light and rendering it both safe and accessible to interested audiences, was initiated and led by Juliet Scott. In a recent paper, she and Antonio Sama (n.d. [2018]) describe the journey thus: 
The archive project started in 2015, after a long period of incubation, when Wellcome Library agreed to house and curate it. Since then the archive has become central to a variety of [Tavistock and other interested parties'] activities and projects. The primary task of the project was to make the archive accessible, however that task was never just a matter of simply declaring it and then doing it because an archive contains a plurality of voices and authors in the Bakhtinian sense. It comprises what Eric Trist [of the Tavistock, and a social psychologist] theorised as an evolving ecosystem, in that authors who are also actors may in turn appear, engage with the project, and then move on.

Working with an archive is thus also to work with actors and agents. As an in-depth excavation of a living organisation, this is necessarily a cautious process; one that takes care to 'make safe' the volatile process of awakening of spirits that happens when working with and releasing the potency of the past.

The Cheshire salt mine had kept the collection preserved within geological strata that make up the earth's own cooling system. During a recent visit to the mine, we were shown the 'room and pillar' method of mining that in the careful excavation of rock salt creates a suitable space for the storage and preservation of archival materials. Used for extracting relatively flat deposits, the room and pillar method (one of the oldest mining methods) involves the extraction of material across the horizontal plane whilst deliberately leaving behind 'pillars' of untouched material to hold up the roof over the opened out areas or 'rooms'. The necessary fine balancing between the scale of extraction (and thus profitability of the mining operation) and the volume of the pillars (and thus miner safety) resonates with the dual purpose of the Institute's post-war organisational consultancy, to enhance industrial productivity whilst also maintaining humane working conditions and worker morale. It also provided an apt metaphor for the archival project work: visiting the salt mine physically connected us with our own careful excavation of the archive, with its seams of discourse and polyphony of voices and conversations that had become ossified over time, and which were about to be reanimated.

By hauling the archive up to the surface and into the light of day, it felt as if we were breathing new life into the Institute as an organisational system. Commonly when an archive is acquired by a library, it is because an individual or an organisation's life has come to an end. This makes archives conventionally an 'end-of-life' artefact as opposed to a living organisational process. Instead of viewing the Institute's archive project as an inanimate and definitively historical artefact of itself, we recognised that it forms part of a living system and that it represents a potentially (re)generative resource. In exhuming the archive, we became particularly aware that 'matter' (or the place from which knowledge derives) can be sentient and emotional. With this comes both the potential for creative use of the material and the responsibility to provide care - both for the materials (in their preservation), and for ourselves. Opening up the archive needed to be done in ways akin to the room and pillar method of mining, providing both space to open up and explore the materials (the rooms), and support (the pillars) to carefully contain emotions associated with the archive, such as the splits and contusions in the Institute's past. Moments in history captured in the archive were likely to still be highly sensitive subjects, and we needed to find appropriate ways to work with them.

As well as engaging in a careful excavation of a plurality of voices, we approached our archive project through the idiom of dreaming. Dreaming here we understood in the following ways: as a state of abstraction, in a trance, or wandering around dreamlike (and the project director's navigating of this state and the plurality of voices and actors being a 'shamanic' aspect of the work); as a condition or achievement that is longed for, an aspiration; and as a series of images, ideas, emotions and sensations that occur involuntarily in the mind during certain stages of sleep. In a spirit of working out loud and in public, dreams were explored in a series of 'social dreaming matrices' held in and with the public in the Reading Room at Wellcome Collection, London, from June 2016 and ongoing. Developed at the Tavistock Institute in 1982, the concept of social dreaming is based on the principle that dreams cannot be determined by the individual as a self-contained entity alone, but must also be shaped by the social and cultural milieu in which the experiences that fuel dreaming take place (Lawrence 2003: 616). In a social dreaming matrix, participants meet and work together in a convened gathering, sharing and making associations to one another's dreams such that individual dreams come to socially interact as links and connections are made (figure 1). 


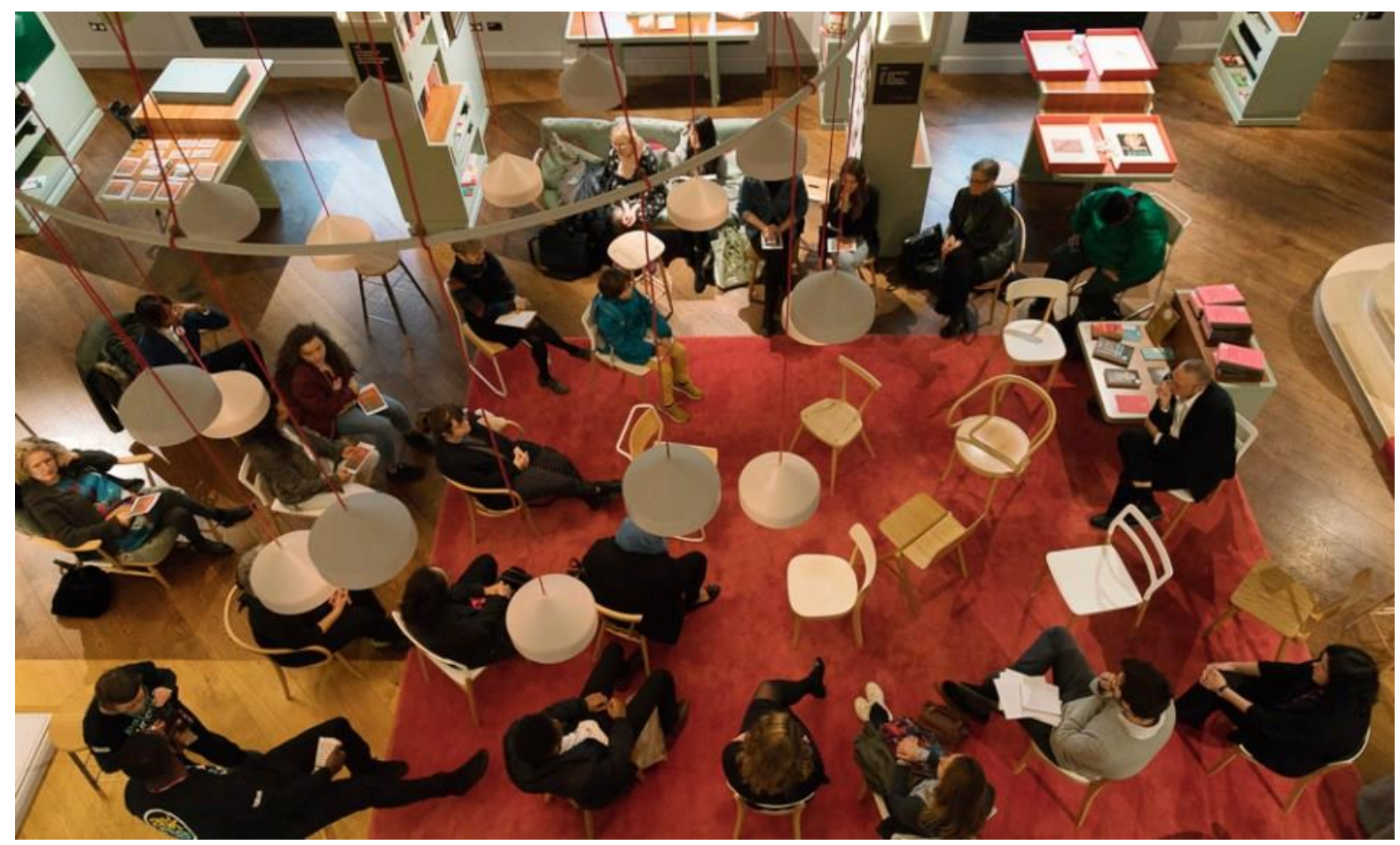

Figure 1: A Social dreaming matrix, Reading Room, Wellcome Library, London ${ }^{\text {vi }}$

The concept of 'matrix' is used to convey the web of feelings, thoughts and emotions present in any social configuration. This interconnectedness allows for an interchange between our unconscious dreams and those shared with and thought through in the group. Following Bion (1970), elements of the mind embodied in dreams are given to a convened matrix which contains them, so they can be picked up by participants in the matrix and transformed into new thought. Emphasis is always on the collective sense-making of dreams made by the group, and not on individuals or individual dream interpretation (Lawrence 2003: 617). At each public matrix, this collective sense-making process was written up by the convenors in public in the Reading Room, and uploaded shortly after to the Institute's archive project website, where all write-ups can be freely seen. The first matrix was held on 24 June 2016, the day after the UK voted in a referendum to leave the European Union and which coincided with the release of the first batch of Tavistock archival material to the public.vii The matrix offered a facilitated space (both room and pillar) in which to explore dreams and feelings about this news, and it did so through the opening up of the archive of one of several organisations (including the NHS, the UN and UNICEF) founded in a war-ravaged Europe concerned to unify.

In the matrix held the following week on 30 June 2016, the distinction between privacy and shared social experiences was explored and expanded upon. Participants shared with the matrix their dreams, that is to say, thoughts and feelings which are normally kept private, or not even shared with ourselves. This took place in a context of growing concerns about the consequences of digital social media applications for personal privacy, and in the immediate context of a museum exhibition space (the Wellcome Reading Room) where many of the artefacts and artworks on display demonstrate the evolution of technologies that delve ever more deeply into the human interior, such as an x-ray machine, a plastinated vivisection and paintings of anatomical dissection. In this setting, the matrix was experienced as a place of collective security where, like a carefully curated archive, things bottled up could be sensitively released and revisited by the group. This and similar moments were captured in a series of social dreaming matrix (SDM) watercolours by Tavistock artist-in-residence Juliet Scott (figure 2). viii Scott's watercolours and other artworks capture (amongst other things) the public social dreaming work done in Wellcome Museum, which forms part of an ongoing journey of archiving ourselves with Wellcome Collection, now in the born-digital stage. In this archiving process, as illustrated by the use of social dreaming matrices at Wellcome, we are retrieving methodologies developed in the Institute's history for use in our present work in and with organisations, which forms part of their and our organisational development. 


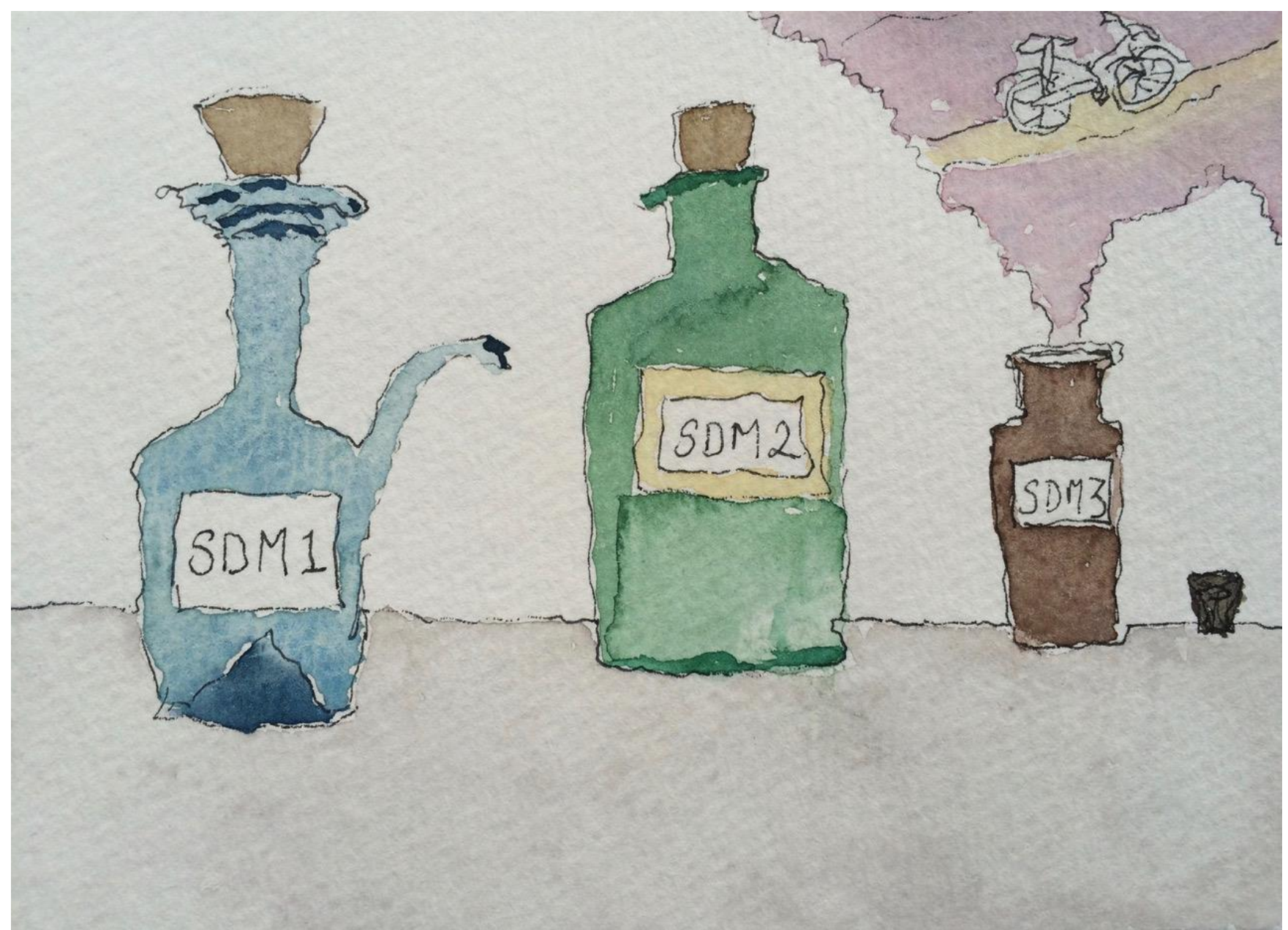

Figure 2: Bottled Up: Watercolour on Langton paper, $14.8 \times 10.5 \mathrm{~cm}$ by Juliet $S$ cott

\section{Encountering ethnographic methodology in the Tavistock Institute's archival past}

Alongside the public social dreaming work at Wellcome, staff of the Tavistock Institute began delving into the as then unsorted and uncatalogued boxes of materials that had recently been retrieved. Perhaps pertinently for this article's argument, the first Tavistock staff to engage with and explore the Institute's historical 'methodological threads' each came from a background in anthropology: Elizabeth Cory-Pearce and Sadie King both with PhD's in social anthropology, and Mannie Sher with a PhD in psychology with an anthropology component. Together they sought projects illustrating 'anthropological threads' in the history of the Institute's work and revealing of an ethnographic orientation to its methods. In this section we highlight aspects of past projects that make these threads and orientations apparent.

The Glacier Project ${ }^{\text {ix }}$ was an industrial collaboration with Glacier Metal Company Ltd, a large manufacturer of plain bearings used in engineering and in particular in the motor industry, which ran from 1950 to 1975. The research took a comparative approach, investigating 'labour turnover' by considering the movement of employees in two factories as a distinctly social process. The project was important in its day because it identified 'culture' as a key element in organisational life, and therefore as a key locus for intervention and change. Elliot Jaques who led the research team later published the research in his book, The Changing Culture of a Factory, and in this sense this study is well known and widely disseminated within a range of management scholarly fields. However, what the recent accessibility of the original Tavistock archival material affords is the possibility to see in detail the in-depth and immersive fieldwork method the project used to collect its data. Tavistock consultants working in and with the client organisation kept detailed and extensive records ranging from diary entries, capturing the more personal and reflective nature of fieldwork data (figure 3); to more worked up (less personalised) 'Field Notes' (figure 4); which, in consultation with the client, could be worked into more succinct propositions and working hypotheses for implementation in the workplace. 


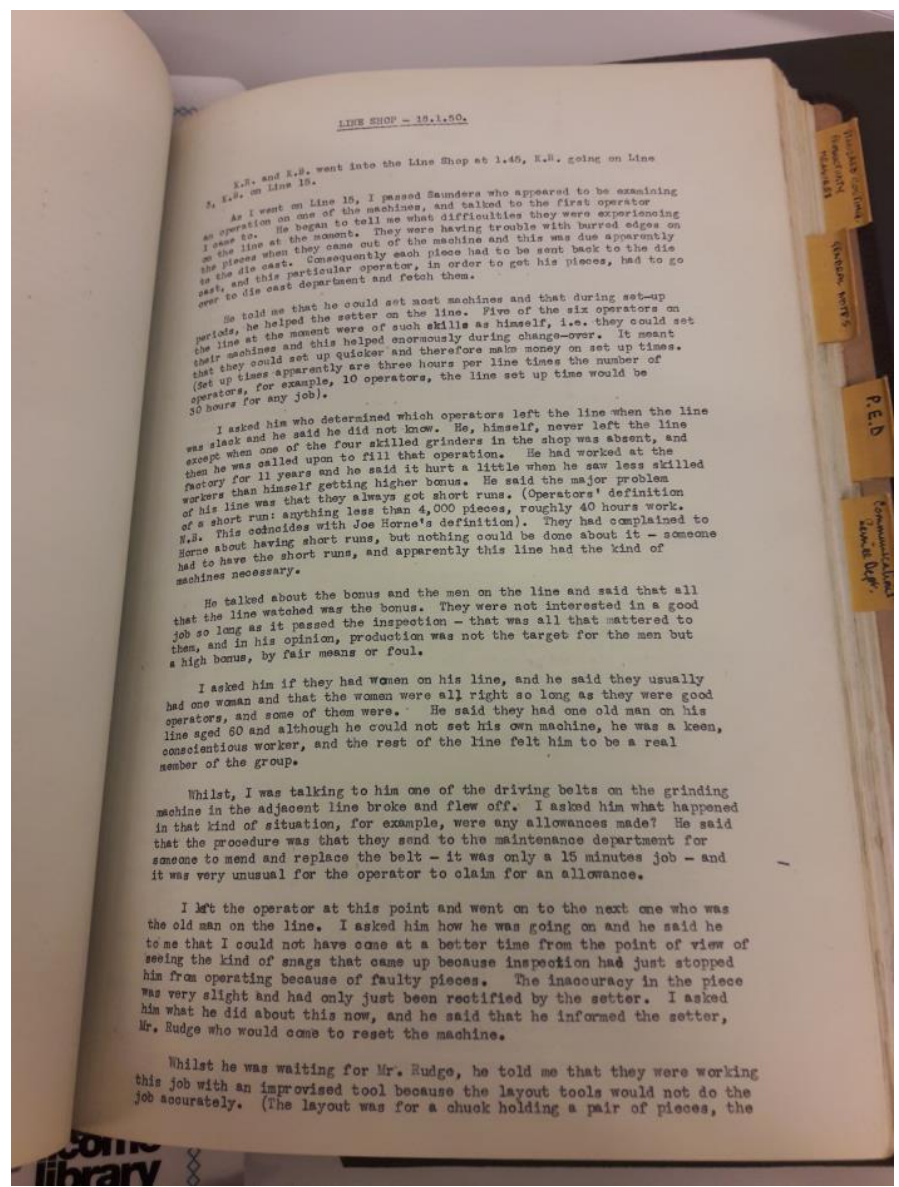

Figure 3: Example of a fieldwork diary entry, Kenneth Bamforth, Glacier Project ${ }^{\mathrm{x}}$

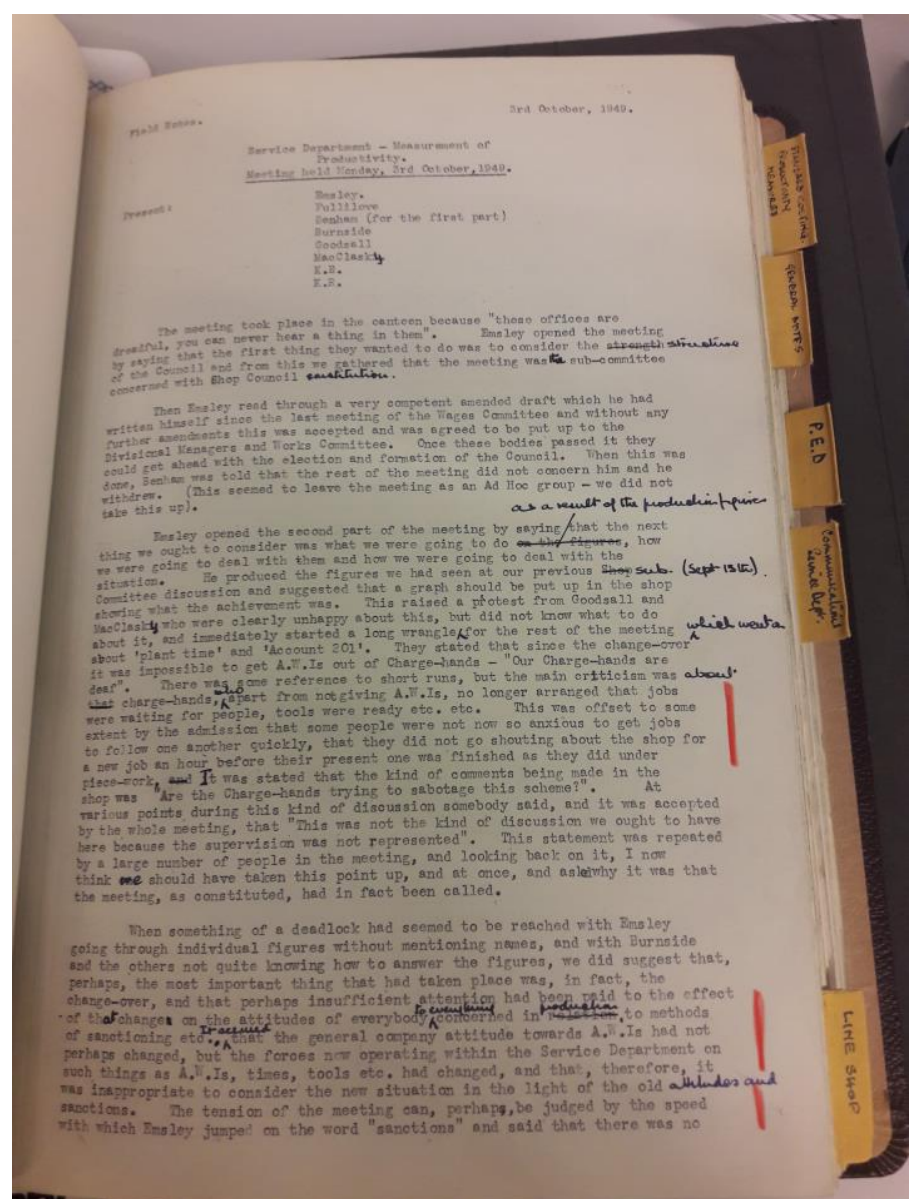

Figure 4: Example of 'Field Notes', A. K. (Ken) Rice, Glacier Project ${ }^{\mathrm{xi}}$ 
When consulting to industry, Tavistock researchers applied psychosocial and anthropological thought, not to the analysis of 'patients' or 'small-scale societies', but to organisational systems and structures in order to understand how human interrelationships and social dynamics shape organisational life, and vice versa. Researchers themselves came from a range of social science backgrounds including psychology, sociology and social anthropology, each taking the workplace to be a key organisational structure in our lives. As such, in the workplace arises the gamut of dynamics that shape human social experience. Whilst these dynamics are not uniquely of interest to anthropologists, they are certainly key to the work of social anthropology (for instance workplace dynamics can revolve around issues of power, hierarchy, age, succession, gender, kinship, the division of resources, all of which are shaped by the values, beliefs and practices that staff as individuals and groups ascribe to). In seeking to understand these dynamics in the workplace as a field site, Tavistock researchers faced challenges similar to any budding ethnographic fieldworker; namely, how to fund the work, and how to negotiate access to the field. In 1949, Tavistock projects were helped by a Government initiative to foster research into the social aspects of industrial organisation, which directly supported the Glacier work. The Government's 'Human Factors Panel of the Committee on Industrial Productivity' funded six higher education graduates to take up a 30-month training programme at the Tavistock Institute, based on experiential learning via immersive fieldwork (i.e. conducting research in and with industry). They were called 'Industrial Fellows' because each had previously worked in an area of industry and, having been sponsored through a programme of higher education (such as a university degree, often by their unions), they were then recruited for applied research training at the Institute. Each Industrial Fellow worked on the Glacier project, plus one other Institute project (Trist 1993).

At this time, a portfolio of work for the National Coal Board ${ }^{\mathrm{xii}}$ was being developed at the Institute in line with a post-war drive to raise energy supplies to fuel the intensification of industrialisation, which was seen as key to Britain's post-war economic recovery. Similar to the Glacier project, the National Coal Board work is an example of an industrial research project that ran from the 1950s for many years. However, unlike Glacier, the National Coal Board work did not entail a straightforward consultant/client partnership. Initiated by the Human Factors Panel of the Committee on Industrial Productivity, the National Coal Board work was interrupted and resumed to be run by different government bodies, the Department of Scientific and Industrial Research (DSIR) and the Medical Research Council, who wished to explore impacts of the introduction of composite working in longwall coal mining. The aim of the work was to understand how the technologies introduced to mechanise coal mining so as to increase economic output were also impacting on worker morale. Morale was captured in terms of things like employee engagement with their work, job satisfaction, and productivity. However, given that the work was evolving in a period of employee strikes and discord between management and unions, enabling fieldwork access for researchers (themselves funded by government bodies) that could genuinely gain a sense of workers' experience of, and engagement with their work, would require careful negotiation.

To broker fieldwork access, the Tavistock Institute was assisted by the requirement that, as part of their "postgraduate training in fieldwork in group relations" (Trist and Bamforth 1951: 38), Industrial Fellows were to visit their former workplaces. Some came with prior mining experience. One in particular, Kenneth Bamforth (who was working with and supervised by Eric Trist), had previously worked as a miner in the Haighmoor seam of a Yorkshire colliery. In correspondence between the Institute and the various government bodies involved in commissioning the work, it is clear that the incorporation of fieldwork researchers with prior mining industry experience into the team was planned and deliberate (figure 5). In the case of Bamforth in particular, who continued to have personal connections in the proposed region for the work, the Institute was introducing a deliberately 'auto-ethnographic element' into the brokering of fieldwork access with specific industrial communities. Whilst the Tavistock Institute provided Industrial Fellows with professional training and development, this was a two-way relationship as Fellows were key to enabling fieldwork access in their industries of prior employment. They lent industry knowledge and contacts to the Institute whilst at the same time improving the trustworthiness and credibility of the Institute within industry workforces.

When Bamforth returned to his prior workplace, he introduced Trist to his colliery where they encountered what they termed 'the Haighmoor innovation'. Miners working the Haighmoor coal seam had self-organised into semiautonomous working groups in which the social and technical aspects of the group's tasks were "joint optimised" (this being the miner's term, not the consultants', according to Trist in a personal interview later in lifexiii). In response to technological changes aimed at increasing economic output, the Haighmoor miners had generated an organisational structure designed by and for themselves that drew on their existing practices and expertise, adapting them to fit the changed circumstances (Trist and Bamforth 1951; Trist 1977). What was so extraordinary about the Haighmoor innovation was that it demonstrated to government and industrial management that investment in 
technology alone would not raise economic productivity, unless 'morale' remained intact. This was accomplished here by a joint optimisation of human (social and psychological) needs with technical tasks, into what became (and is still) theorised as a 'socio-technical system'.

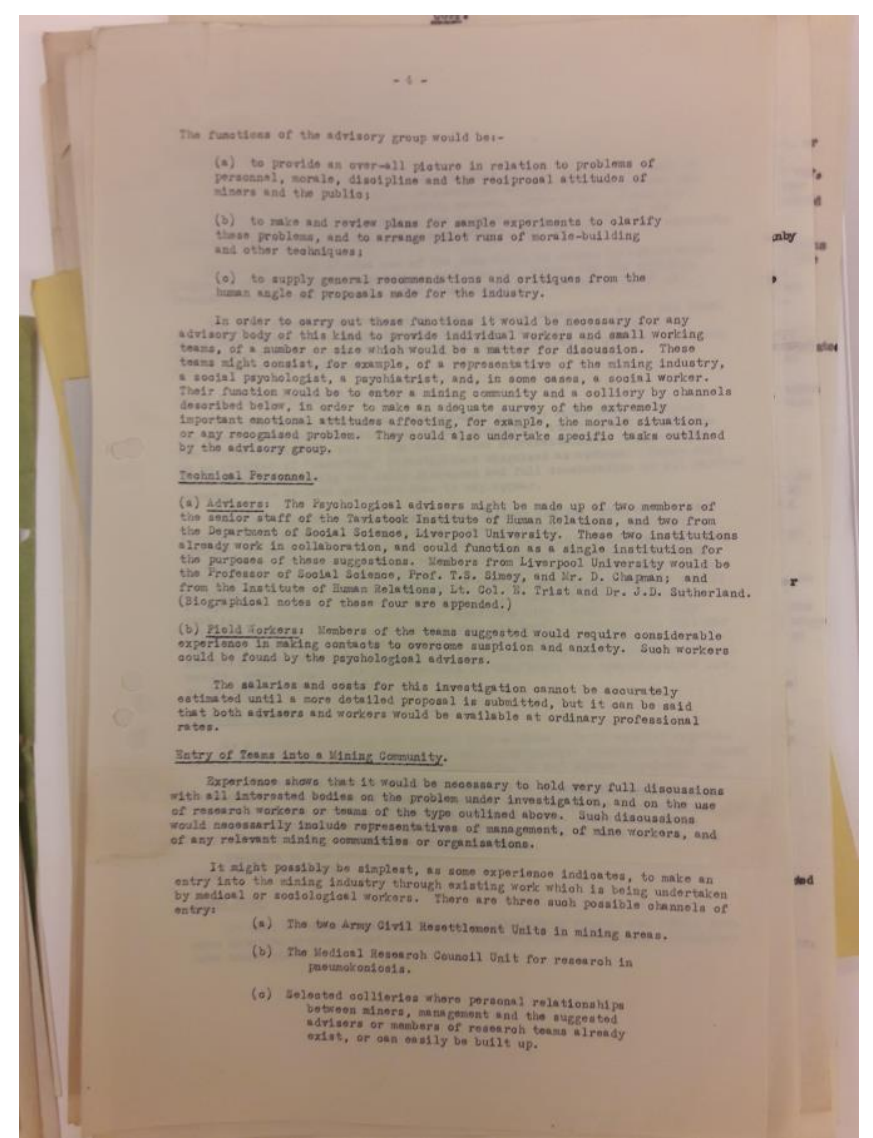

Figure 5: "Entry of Teams into a Mining Community” [via] “(c) Selected collieries where personal relationships already exist", Tavistock Institute correspondence with the Department of Scientific and Industrial Research ${ }^{\text {xiv }}$

The National Coal Board work was generating evidence of alternative approaches to mechanisation than Fordist and Taylorist models. From a Tavistock perspective, industry problems were understood to be problems of morale, that is of "problems of human relations"xv (hence the name of the Institute and its journal). Fordist and Taylorist approaches to factory organisation were already being shown in a growing body of US-based human and industrial relations research to be causing monotony of work, a loss of worker morale, fatigue, and a corresponding reduction in economic output below that which new technology had been forecasted to deliver (Mayo 1933; Roethlisberger et al 1939; Warner 1937; 1952; and Gardner 1945).xvi The Haighmoor findings complemented this work, showing that where workers can self-organise into groups that offer each worker a degree of self-leadership or autonomy in their work, both human morale and economic productivity will be raised. Whilst socio-technical systems (STS) theory has since flourished in both organisational research practice and management studies scholarship, the importance of an auto-ethnographic component to the Institute's field research has become overlooked; so much so, that Trist himself later in life pointed out in an interview that whilst the invention of an STS approach has become frequently attributed to him, the innovation was not his, but was derived from an existing one he and Bamforth had observed in a Yorkshire colliery (for the interview source, see endnote xiii). The Haighmoor miners' innovation demonstrated that when people are given some responsibility for their work, they will be more responsible in their work. These key principles - of 'socio-technical systems' theory (that productivity requires the joint optimisation of social and technical needs); and of the 'semi-autonomous self-organised working groups' method (that people affected by the problem being consulted to, should be directly involved in devising ways of improving upon it) - became (and have remained) foundational to Tavistock Institute consultancy work.

These findings were taken up into and further developed in the ongoing work of (initially) A. K. Rice and (later with) Eric J. Miller in the Calico Mills Textile Industry Studies, xvii from 1947 to 1970. The Calico Mills studies took place at the Ahmedabad Manufacturing and Calico Printing Company (a subsidiary of Sarabhai Industries) in Ahmedabad, India, with the Sarabhai family owner as client. Rice worked directly with the client in a 'Development Group' which included Gautam Sarabhai, the Company's Chairman, a Mill Manager and a Works Manager. Together they 
introduced changes in work organisation into a range of experimental loom sheds, which included the establishment of semi-autonomous work groups with responsibility for textiles production and the maintenance of a group of looms. In general, the self-led work group approach allowed for the withdrawal of higher management from the governing system of the sheds, and led to a reduced number of people reporting directly to supervisors, as greater degrees of authority and responsibility were assumed by the group. More specifically, each shed was intended as a testbed for understanding the effects of the introduced changes, and in particular of the reconfiguration of work organisation (and hierarchy) as this interacted with established patterns of authority and leadership in Indian culture (Rice 1953; 1958).

Whereas the National Coal Board work methodology incorporated an auto-ethnographic element to ensure trusted fieldwork relationships with mining communities, in Ahmedabad fieldwork was greatly enabled by the Sarabhai family company employing Eric Miller as a resident internal consultant. Miller had recently completed a PhD in social anthropology on the changing place of hereditary caste in determining occupation and position (n.d. [1953]). Having conducted doctoral fieldwork in Malabar, India, Miller's understanding of caste in relation to role and authority was historically and ethnographically rich, and his approach to his consultancy in Ahmedabad is similarly characteristically ethnographic. Unlike Rice, Miller lived on site and having already worked as an internal consultant to the American textile manufacturer, Ludlow Ltd, at its Calcutta plant, he had learned at least two local dialects (Olya Khaleelee, personal communication, 17 October 2016). Although Rice had studied anthropology at undergraduate level, Miller's longer term doctoral research in Malabar, as well as his internal consultancy experience in Calcutta, meant he was better placed to grasp just how radical the changes introduced by the Calico Mills project were in terms of local understandings of work organisation, and just how strong the pull of established patterns of authority and hierarchy in Indian culture would be (Miller 1975; Cory-Pearce n.d. [2018]). In all his consultancy work, Miller wrote detailed descriptive diaries and notes of the sites and activities that he participated in and observed. However, now working as a consultant (and in distinction to his academic work), Miller now distilled the research literature he reviewed, as also his own ethnographic data, into succinct working hypotheses on areas of concern to the issues being consulted to (such as 'resistance to change', for instance). In the movement from fieldwork notes and diaries, to lists of propositions that were distilled via a back and forth consultation with the client working groups to produce shared working hypotheses, the archived materials of the Calico Mills studies (as other historical Tavistock projects) show the process by which detailed ethnographic data can be operationalised in the action-orientated research and consultancy sense (rather than being operationalised from field data to published monograph in the scholarly sense).

One final example of Tavistock work that provides a rich illustration of this 'operationalisation of ethnographic fieldwork data into action-orientated research and consultancy process' is the Jebsens Project of Change.xviii Jebsens was one of a number of shipping studies conducted by the Institute during the 1970s and 1980s. At this time, Jebsens (and the shipping industry in general) faced a problem of workforce recruitment and retention. By seeking to improve the conditions of working life for those at sea (and in relation to their connections with onshore staff and to society more broadly), the Jebsens work was intended to raise staff recruitment and retention. As with the previous examples, Institute consultants worked not only with management but also with worker groups and their representatives (including the National Union of Seamen and the Merchant Navy and Airline Officers Association) in a 'whole system' or social ethnographic approach. Again, the fieldwork is characteristically ethnographic, with Institute researchers boarding vessels and living amongst staff. Institute staff kept detailed voyage diaries which capture the texture of shipboard life and describe the experiments that were taking place in organisational design, as Institute and Jebsen's staff explored ways to improve the sense of community in working life at sea.

These voyage diaries and organisational design experiments are now available for research via the archive. When Cory-Pearce, King and Sher first conducted their research on Tavistock archival material in a study room at Wellcome Library in 2016, they looked at some of the shipping material. Their conversation shifted from the immediate materials in hand, to a realisation that in the coming together of different social science disciplines at the Tavistock (where research is action-orientated and thus problem- not discipline-centred), insights from one discipline could be brought to bear fruitfully upon another:

Sadie King: In the shipping work for instance, the fieldwork is anthropological in theory, method and analysis.

Mannie Sher: Observing and reflecting is also clinical psychological. When I'm working with a client, it's a cultural system that I enter into and I am a participant observer. I try not to get caught up in the dynamics. I step in and I observe, and when I start to see what I am experiencing and feeling, this is data for use. From this experience, you can provide insight to the client. 'The system is making me feel this. So how does this feedback help shape the system to work more effectively?' In transference and counter-transference, the client projects parent or authority status onto the analyst, and similarly so in anthropological fieldwork. Working ethnographically, you also experience powerful mental 
projections. Anthropologists can learn from the psychoanalytical use of transference and countertransference. It can be a valuable tool in the participant-observer approach: as an anthropologist, making notes in fieldwork you are trying to describe a society through encounters with individuals. So how are you going to make that leap? You could start with the projected mental images. For instance, any person you meet in fieldwork, their reaction to you is going to be coloured by their history, their experience, their perception of you, and so on.

Elizabeth Cory-Pearce: Like, if you find you're being perceived of as the Empire's representative or colonialism's agent in fieldwork?

\begin{abstract}
Mannie Sher: Yes, and the normal reaction is to resist and say, 'No', and to oppose the idea. Rather, you could say, 'Yes, I see you have that view', and then explore it and use it. These projected images can get in the way. However, if you're aware of them, the transference can be a way in to understanding social and mental structures [i.e. of cultivating an ethnographic sensibility, of experiencing another's way of thinking]. It can be a welcome source of data.

Anthropologists could make more use of this. The leap we are making in fieldwork is from the individual's experience (which is much easier to grasp hold of in the research because it's there, visible, in-the-moment) to social, cultural, economic and political levels. ${ }^{\text {xix }}$
\end{abstract}

This interdisciplinary (or even transdisciplinary) working characterises the Institute's history, and, moreover, in this instance illustrates how anthropologists, by drawing on insights from psychology, might pay greater attention to the perceptions (and preconceptions) that people project onto them in fieldwork encounters. Not only is this data that can be grasped relatively quickly (always a concern in commercially situated research), it also may allow the fieldworker to more comfortably justify making the leap from momentary fieldwork encounters to broader social and systemic interpretations. Just as ethnography and auto-ethnographic approaches have enriched the Tavistock's methodologies, so ethnographic approaches in anthropology can be enriched by drawing on a range of social science disciplines.

Examples of the Tavistock's work given here are taken from industrial settings, but the Institute worked on organisational design innovation in a wide range of settings, including social and health care services. ${ }^{\mathrm{xx}}$ Work in care homes and hospitals (such as the Fulbourn Hospital Innovation Project ${ }^{\mathrm{xx}}$ and the Geriatric Hospital Care

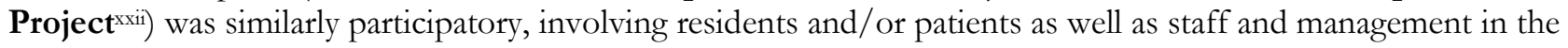
research. In the Fairhaven Project xxii cared-for young adult residents were enabled to run their own accommodation; and in the Cotswold Community ${ }^{\text {xiv }}$ project (a therapeutic community for young boys) Institute staff worked across the organisation, including with its residents, to facilitate greater self-organisation and autonomy as the organisation transitioned from local authority control to the voluntary sector. In all these projects, the Institute's characteristically holistic approach (which takes into account not only relationships between management and staff, but also organisational members as a whole, and the wider society in which the organisation exists) will chime with those trained in ethnographic research.

Having an official archive allows us to revisit, recover and repurpose historical Tavistock methods in terms of our current practice. In this article, we encourage others to do the same in their research and teaching of anthropology. Archives offer a way into understandings that can be missed by drawing on existing historical canons alone, as that which is published within any scholarly canon tells us as much about positionalities of power as it does about knowledge and expertise (Cory-Pearce 2007). The Tavistock Institute archive offers up great scope for challenging oft repeated histories of the development of organisational research as both scholarly discipline and practitioner field. This scope for critical revision includes recovering the effaced history of anthropology's contribution to the development of these fields. Of course, not all Institute staff were trained in anthropology. For instance, as previously mentioned, Eric Trist was a social psychologist, however it is notable that upon graduation he went to the University of Yale's Institute of Human Relations to work under anthropologist Professor Edward Sapir. Today Trist is remembered by colleagues as being committed to a distinctly cross-disciplinary Tavistock endeavour (David Armstrong, personal communication, 6 July 2018). We hope the examples given here of the use of ethnography as part of that cross-disciplinary (and cross-sectoral) effort provide sufficient illustration to convince you of the significance of anthropology's influence on organisational research.

\title{
Conclusion: Can we teach organisational research ethnographically today?
}

David Mills (2006) provides a fascinating analysis of a post-war rejection of commercial industrial research by newly tenured 'captains of anthropology' as a young university science. His account offers an apt comparator to the early years of the Tavistock Institute described here, when not all anthropologists rejected the interest shown by industry. The Institute's archive tells of both the perils and rewards of mixing academic purity with practical risk (c.f. Mills 
2006). Orphaned (metaphorically speaking) by the splitting of the Tavistock Group into a government funded NHS Clinic and a financially independent Institute, the latter had always to work for commercial clients to finance its operations (Aram, n.d. [2017]). Yet this orphan vulnerability may also have been a strength. The Institute simply could not afford to say no to industrial work, and, moreover, came into existence precisely through a wish to engage the social sciences more directly in the growth and development of people and organisations than had previously been the case. With many recent changes to UK public funding of higher education, and, also, a recent application for a Royal Charter by the Royal Anthropological Institute, this century may yet witness a more publically engaged discipline, respondent to inquiries by industry, government and citizens at large (and the government's development of a 'Knowledge Exchange Framework' surely requires it). In this the discipline might take heart from the observation that whilst some clearly more 'bread and butter' projects have been undertaken to keep the Institute afloat, nevertheless, where the Institute felt issues of human welfare to be at stake commercial work was either turned down or terminated (Aram n.d. [2017]).

Presently we contend anthropologists are far more likely to be familiar with the 'shop floor ethnographies' of Max Gluckman's 'Manchester School' (Emmett et al 1982; Frankenberg 1982) than with the work of the Tavistock. This was not always so. In the post-war period anthropologists - scholarly and applied - not only knew one another and one another's work, they influenced and contributed positively to one another's professional paths. Elizabeth Bott (who studied psychology at the University of Toronto followed by an MA in anthropology at the University of Chicago) came to the UK to work at the London School of Economics (LSE), because she was inspired by Malinowki's approach to fieldwork (Bott [Spillus] 2007). At the Tavistock Institute she conducted a major study of kinship networks in London's east end, which in 1956 became her $\mathrm{PhD}$ and subsequently a research monograph (Bott [Spillius] 1957). Associated with the Manchester School, it is clear from Gluckman's preface to her monograph that Bott was a colleague of some regard. Whilst at the LSE, Bott shared an office with Edmund Leach. In a recent anthology of her work, Bott reflects generally on the importance of an anthropological training to her career, and on the significance of her interactions and discussions with Leach more specifically (Bott [Spillius] 2007). Eric Miller, who also held a PhD in anthropology, was supervised by Meyer Fortes at the University of Cambridge during the post-war period of engagements with 'captains of industry' that Mills (2006) describes. Fortes was one of the anthropologists involved, and it was through this dining and networking that Miller's first consultancy interview (with American textile manufacturer Ludlow Ltd) came about.

However, by 1972, although Nader refers to Bott's study of kinship in London's east end in her broader call for anthropologists to do more to study 'ourselves' (1972: 301), the Tavistock Institute (where Bott conducted the study) goes unmentioned. In 1994, Susan Wright, in her introduction to an edited collection on the anthropology of (not in) organisations, refers only in passing to the Institute's development of 'sociotechnical systems'. By comparison, parallel studies in industry - Mayo's Hawthorne Studies in an electricity company in Chicago and the Manchester School's work - are described in pages of detail. In 2006, Thomas H. Eriksen published a book calling urgently for a more public anthropology. In a similar vein, Robert Borofsky launched a 'Public Anthropology' book series intended to establish and grow the same. More recently, two special issues of the Royal Anthropological Institute's journal have been dedicated to topics convergent with the Tavistock's work on organisational design and process, and the reconfiguration of labour relationships within changing workplaces: 'Dislocating Labour: Anthropological Reconfigurations', edited by Penny Harvey and Christian Krohn-Hansen (2018); and 'Meetings: Ethnographies of Organizational Process, Bureaucracy, and Assembly', edited by Hannah Brown, Adam Reed and Thomas Yarrow (2017). In this scholarship, the ethnographically informed analytical work of the Tavistock Institute is absent, yet surely relevant?

Despite the growing number of anthropology journals on the market, markedly little of their content describes industrial or government client work (where consultancy work is covered, it tends to be in the international development sector). Perhaps because of the problem-centred nature of action-orientated research, the Tavistock's work has become overlooked by an increasingly discipline-oriented anthropology. Perhaps, too, in an increasingly consultancy- and evaluation-focussed market for applied research, the Tavistock's work has become more substantially represented in practitioner reports than in scholarly publications. Whatever the reasons for the eclipse, we argue that academic anthropology today would do well to look outside of its disciplinary canon to seek other theories, methods, cases, arguments and ideas. For the Tavistock, an ongoing tension between the desire to publish in scholarly journals (including its own) and the requirement to produce reports and similar for commercial clients continues to be a perpetual struggle. Yet it is this which renders the archive so prescient, as it contains far more research findings than have yet been published. 


\section{References:}

Abraham, F. (2013) 'The Tavistock Group', pp 155-173 in M. Warner and M. Witzel (ed.s), The Oxford Book of Management Theorists (First edition), Oxford: Oxford University Press.

Aram, E. (n.d. [2017]) 'On Being an Orphan; an Untold Story', keynote delivered at the symposium 'In the Shadow and Light of the Archive' as part of the Tavistock Institute's Seventieth Anniversary Festival, 'Human Relations in Our Time', London, 17-20 October 2017. (Retrieved 7 November 2018 from: http://www.tavinstitute.org/wp-content/uploads/2018/10/On-Being-an-Orphan-by-Dr-Eliat-Aram-web.pdf)

Armstrong, D. (2017) 'Psychoanalytic' Study and the Ethical Imagination: the Making, Finding and Losing of a Tradition', Organisational and Social Dynamics, Volume 17 (2): 222-234

Bakhtin, M. M. (1993) Problems of Dostoyevsky's poetics. Edited and translated by C. Emerson. Minneapolis: University of Minnesota Press.

Bion, W. R. (1970) Attention and interpretation London: Tavistock Publications

Bott [Spillius], E. (1957) Family and Social Network. London: Tavistock Publications

Bott [Spillius], E. (2007) Encounters with Melanie Klein: Selected Papers of Elizabeth Spillius London: Routledge

Brown, H. Reed, A. and Yarrow, T. (ed.s) (2017) 'Meetings: Ethnographies of Organizational Process, Bureaucracy, and Assembly', Journal of the Royal Anthropological Institute Volume 23 (S1)

Burnes, B. and Cooke, B. (2013) 'The Tavistock's 1945 invention of Organization Development: early British business and management applications of social psychiatry', Business History, Volume 55 (5): 768-789

Cory-Pearce, E. (n.d. [2018]) 'Recovering the Utility of Anthropology: Eric Miller and the application of anthropology to improving industrial and urban lives', unpublished paper presented at the Association of Social Anthropologists of the UK and Commonwealth (ASA) conference, 'Sociality, Matter and the Imagination: Recreating Anthropology', University of Oxford, 18-21 September 2018

Cory-Pearce, E. (2007) 'Locating Authorship: Creativity and Borrowing in the Writing of Ethnography and the Production of Anthropological Knowledge', pp 127-149 in E. Hallam and T. Ingold (eds) Creativity and Cultural Improvisation, Association of Social Anthropologists Monograph 44, Oxford: Berg

Cummings, S., Bridgman, T. and Brown, K. G. (2016) 'Unfreezing change as three steps: Rethinking Kurt Lewin's Legacy for Change Management', Human Relations Volume 69 (1): 33-60

Emmett, I. and Morgan, D. H. J. (1982) 'Max Gluckman and the Manchester Shop-floor Ethnographies', pp 140-165 in Frankenberg, R. (ed) Custom and Conflict in British Society Manchester: Manchester University Press

Eriksen, T. H. (2006) Engaging Anthropology: The Case for a Public Presence Oxford: Berg

Frankenberg, R. (1982) ‘A Social Anthropology for Britain?’ pp 1-35 in his edited Custom and Conflict in British Society Manchester: Manchester University Press

Gardner, B. B. (1945) Human Relations in Industry Chicago: Richard D. Irwin

Harvey, P. and Krohn-Hansen, C. (ed.s) (2018) 'Dislocating Labour: Anthropological Reconfigurations', Journal of the Royal Anthropological Institute Volume 24 (S1)

Heller, F. (1993) ‘Another Look at Action Research’, Human Relations Volume 46 (10): 1235-1242

Human Relations: A Quarterly Journal of Studies towards the Integration of the Social Sciences (1947) Volume 1: Number 1, pp 1-140 (The Tavistock Institute of Human Relations, London, and the Research Centre for Group Dynamics, Cambridge MA, USA) 
Jaques, E. (1951) The Changing Culture of a Factory: A Study of Authority and Participation in an Industrial Setting London: Tavistock-Routledge

Lawrence, G. (2003) 'Social Dreaming as Sustained Thinking', Human Relations Volume 56 (5): 609-624

Mayo, E. (1933) The Human Problems of an Industrial Civilization New York: Macmillan

Miller, E. J. (n.d. [1953]) 'An analysis of the Hindu caste system in its interactions with the total social structure in North Kerala', unpublished $\mathrm{PhD}$ dissertation, University of Cambridge

Miller, E. J. (1954) 'Caste and Territory in Malabar', American Ethnologist Volume 56: 410-420

Miller, E. J. (1975) 'Socio-technical systems in weaving, 1953-1970: A follow up study', Human Relations, Volume 28: $349-86$

Miller, E. J. (1993) 'Preface', pp vii-xix in his From Dependency to Autonomy: studies in organization and change London: Free Association Books

Mills, D. (2006) 'Dinner at Claridges? Anthropology and the 'Captains of Industry', 1947-1955', pp 55-70 in Pink, S. (ed.) Applications of Anthropology: Professional Antbropology in the Twenty-first Century Oxford: Berghahn

Neumann, J. (2005) 'Kurt Lewin at the Tavistock Institute', Educational Action Research Volume 13 (1): 119-136

Nader, L. (1972) 'Up the Anthropologist: Perspectives Gained from Studying up', pp 284-311 in D. Hymes (ed) Reinventing Anthropology New York: Pantheon (Random House)

Rice, A. K. (1953) 'Productivity and social organisation in an Indian weaving shed: an examination of the sociotechnical systems of an experimental automatic loom shed', Human Relations Volume 6: 297-329

Rice, A. K. (1958) Productivity and Social Organization: The Abmedabad Experiment London: Tavistock Publications

Roethlisberger, F. J. and Dickson, W. J. (1939) Management and the Worker: An Account of a Research Program Conducted by the Western Electric Company, Hawthorne Works, Chicago Cambridge, MA: Harvard University Press

Sama, A. and Scott, J. (n.d. [2018]) 'A Polyphonic Dialogue with the Tavistock Institute of Human Relation's (TIHR) Archive: Working with the Past, Present and Future as Organisational Development and Customisation of TIHR traditions', unpublished conference paper presented at the $78^{\text {th }}$ Annual Meeting of the Academy of Management, 'Improving Lives', University of Chicago, 10-14 August 2018

Trist, E. (1977) 'A Concept of Organizational Ecology', Australian Journal of Management Volume 2 (2): 161-175

Trist, E. (1993) 'Guilty of Enthusiasm’, pp 193-225 in A. G. Bedeian (ed.) Management Laureates Volume 3, Greenwich, CN: JAI Press

Warner, W. Lloyd (1937) A Black. Civilization: A Social Study of an Australian Tribe New York: Harper and Row

Warner, W. Lloyd (1952) Structure of American Life: Being the Munro Lectures delivered in the University of Edinburgh April-May 1950 Edinburgh: Edinburgh University Press

White, A. (n.d. [2016]) 'From the Science of Selection to the Psychologising of Civvy Street: The Tavistock Group, 1939-1948', unpublished PhD dissertation, University of Kent

White, A. and Monninger, D. (n.d. [2017]) 'Sites of Selection', unpublished paper presented at the symposium 'In the Shadow and Light of the Archive', as part of the Tavistock Institute's Seventieth Anniversary Festival, 'Human Relations in Our Time', London, 17-20 October 2017

Wright, S. (1994) 'Culture in Anthropology and Organizational Studies' in her (ed.) Anthropology of Organisations London: Routledge 


\section{Notes:}

i The foundations of this article were first presented at the Royal Anthropological Institute 'Teaching Anthropology' Annual Conference, University of Oxford and Oxford Brookes, Oxford, on 7 December 2017. It draws on material presented previously at the Tavistock Institute (2 May 2018 http://www.tavinstitute.org/projects/eric-miller-application-of-ananthropological-training-to-tihr-work/ and 19 October 2016 http://www.tavinstitute.org/projects/the-anthropologicalthread-in-tihr-archive); at the Anthropology in the Professional World seminar series at the UCL Department of Anthropology (30 November 2016); and at the Academy of Management Annual General Meeting, Chicago (14 August 2018), and has benefited from various discussions with colleagues and other contributors throughout. Our thanks are due to Frances Abraham, Eliat Aram, David Armstrong, Olya Khaleelee, Sadie King, Jean Neumann, Antonio Sama, and Mannie Sher. Any misrepresentation or error remains our own.

ii Vocation is used here in both senses of the word (a strong feeling or 'calling' to a particular occupation, regarded as worthy and requiring dedication; and a trade or profession) to refer to both anthropological scholarship and its application to other areas of professional practice, for instance consulting to industry.

iii The Tavistock Institute Archive is publically available at Wellcome Library, Euston Road, London. You can access all catalogued projects via the Tavistock Institute's Archive Project webpage at http://tihr-archive.tavinstitute.org/the-archive/ and also via the Wellcome Library catalogue webpage (http://archives.wellcomelibrary.org), by searching for 'Tavistock Institute' or using the reference 'SA/TIH'.

iv See the founding document, 'Document 1', page one of the Tavistock Institute's Publications Ledger, (Wellcome Catalogue Number SA/TIH/B/1/1/2).

v Wellcome Library catalogue reference SA/TIH/B/2/9

${ }^{v i}$ http://tihr-archive.tavinstitute.org/festival-social-dreaming-matrices-4-friday-20-oct-2017/

vii http://tihr-archive.tavinstitute.org/social-dreaming-note-2/

viii http://tihr-archive.tavinstitute.org/social-dreaming-note-2-thursday-30-june-2016/

ix Wellcome Library catalogue reference SA/TIH/B/2/2

x Wellcome Library catalogue reference SA/TIH/C/1/1

xi Wellcome Library catalogue reference SA/TIH/C/1/1

xii Wellcome Library catalogue reference SA/TIH/B/2/3

xiii ‘A Conversation with Eric Trist', Retrieved 7 November 2018 from:

https://www.youtube.com/watch?v=OEMaSTOrqBA

xiv Wellcome Library catalogue references SA/TIH/B/2/3/1/6

${ }^{x v}$ Eric Trist in National Coal Board project folder, Wellcome Library catalogue reference SA/TIH/B/2/3/1/1.

xvi See the University of Harvard Business School's Baker Library website for relevant studies on human relations in industry in America (https://www.library.hbs.edu/hc/hawthorne/rl-selected.html\#SDHR).

xvii Wellcome Library catalogue reference SA/TIH/B/2/4

xviii Wellcome Library catalogue reference SA/TIH/B/2/52

xix This and other conversation that unfolded when consulting the archive are written up on the archive project's website blog (see http://tihr-archive.tavinstitute.org/what-is-the-blog/ and http://tihr-archive.tavinstitute.org/conversationsarchive/ for further illustration).

xx These projects and many others are listed on the Tavistock Institute Archive Project website which links directly to the relevant pages of the Wellcome Library catalogue here: http://tihr-archive.tavinstitute.org/the-archive/.

xxi Wellcome Library catalogue reference SA/TIH/B/2/60 
xxii Wellcome Library catalogue reference SA/TIH/B/2/64

xxiii Wellcome Library catalogue reference SA/TIH/B/2/51

xxiv Wellcome Library catalogue reference SA/TIH/B/2/58 